\title{
SOBRE O ESTATUTO DA FILOSOFIA NO ÂMBITO DAS RELIGIONSWISSENSCHAFT
}

\section{ABOUT THE STATUTE OF PHILOSOPHY IN THE CONTEXT OF RELIGIONSWISSENSCHAFT}

Luiz Carlos Rocha*

\section{RESUMO}

O presente trabalho tem como objetivo fundamental explicitar o papel e o estatuto da filosofia no âmbito das ciências da religião (Religionswissenschaft), no concernente aos aspectos do fenômeno religioso, este entendido enquanto "espaço" possibilitador de experiência real e vital ao ser humano. Ao estabelecer tal relação, fica evidenciado a característica originária da filosofia frente ao fenômeno religioso, a saber, sua postura crítica (kritische Haltung), condição inerente de sua estrutura genética.

PALAVRAS-CHAVE: Filosofia. Ciências religiosas. Fenômeno religioso. Experiência.

\section{ABSTRACT}

The present work has as fundamental objective to explain the role and statute of philosophy in the context of religion sciences (Religionswissenschaft), regarding the aspects of the religious phenomenon, this understood as a "space" enabler of real and vital experience to the human being. When establishing such relation, becomes evident the originating characteristic of philosophy in front of the religious phenomenon, namely, its critical posture (kritische Haltung), condition inherent of its genetic structure.

KEYWORDS: Philosophy. Religious sciences. Religious phenomenon. Experience.

\section{Introdução}

O tema dessa reflexão esconde uma "situação" nova dentro do panorama da compreensão da realidade do mundo exterior, ou seja, daqueles aspectos que conferem graus de sentido à vida humana, a exemplo das questões metafísicas, em contraposição aos limites e/ou questões puramente físicas. Tal situação está manifestada no reflexo do giro antropocêntrico que caracteriza expressamente a modernidade adulta. ${ }^{1}$

\footnotetext{
* Mestrado e Doutorado em Filosofia pela Universitat Ramon Llull, URL, Barcelona, Espanha. Professor Adjunto da Universidade Federal de Alagoas - UFAL, Campus Arapiraca (AL), Brasil. E-mail: ludeus@yahoo.com.br

${ }^{1}$ O Prof. José Carlos Aguiar de Souza, em sua obra O Projeto da Modernidade, especificamente no segundo capítulo - A legitimação da Idade Moderna -, constrói uma afirmação que legitima essa modernidade adulta, ou
} 
$\mathrm{O}$ aspecto mais notório desse giro está configurado no que poderíamos chamar de epistemologischen Gebiet (território epistemológico), i.é., a busca por um conhecimento radical do homem obtido agora pelas ciências religiosas, em oposição ao estudo filosófico do Ser Supremo.

Dito isto, parece-nos oportuno mencionar aqueles elementos imprescindíveis que remarcam o estatuto mesmo da Filosofia no tema proposto.

O primeiro deles é a visibilidade das reações causadas por dois fatores importantes: por um lado as suspeitas suscitadas pela filosofia e, por outro, a curiosidade da mesma em alavancar um processo de reflexividade. Tais reações poderão ajudar enormemente na conotação existente no contexto do espaço acadêmico ao deparar-se com o tema religioso, visto que a filosofia demarca, especialmente nesse aspecto, dois critérios fundamentais: o rigor e a tolerância, visto serem estes os aspectos que possibilitarão a construção mesma do estatuto ou da identidade da filosofia nesse campo de estudo, diferenciando-a enormemente de toda e qualquer pretensão teológica.

Seguindo tal enumeração, podemos inferir que no âmbito das Religionswissenschaft, a filosofia ocupa um espaço fundamental, tendo em vista que esta não ousa falar do Objekt (objeto) da religião, senão do chamado religiöses Phänomen (fenômeno religioso). ${ }^{2}$

Outro fator importante que formaliza esse estatuto da filosofia na relação que estamos estabelecendo, diz respeito a própria via de compreensão, ou seja, a disposição racional e autônoma, portanto, a-confessional, não adaptando-se, portanto, a nenhuma tradição religiosa (e tampouco ritualística), institucional ou, também, antirreligiosa ou a-religiosa. Ademais, a mesma não necessita do «principium fidei» para impulsar sua atividade reflexiva sobre as manifestações diversas do fenômeno religioso. No entanto, isso não implica dizer que seu ponto de partida carece de todo e qualquer pressuposto, portanto de um marco totalmente neutral e, de certo modo, completamente virgem de conteúdo, pois "pensar é sempre 'repensar' e, portanto, pensar desde uma situação determinada."3

seja, “a afirmação-do-self como um programa existencial." Relendo Hans BLUMENBERG, o autor expõe que "a afirmação-do-eu significa que o homem leva em consideração sua situação histórica, determinando para si mesmo como irá tratar o mundo em que vive e tomando decisões diante das possibilidades que lhe são oferecidas". (SouZA, J. C. A., 2005, p. 69-70).

2 Essa peculiaridade da filosofia não está limitada tão somente às religiões "teístas", pois uma de suas tarefas consiste, exatamente, em contrapor a linguagem direta da religião à linguagem indireta da filosofia da religião que, em última instância, consiste numa metalinguagem, visto que àquela, ou seja, a linguagem direta, é competência estrita da Teologia.

3 Cf. Lluís I FONT, Pere, L’estatut de la Filosofia de la Religió. n. 5, p. 13. Apostilha (Livre docência) Universitat Autònoma, Barcelona, 1991. (26f.). 
Noutras palavras, ao direcionar seu "olhar" ao fenômeno religioso, a filosofia necessita reconhecer os pressupostos fundamentais do fenômeno enquanto tal e, além do mais, colocarse numa atitude de profundo respeito. Nesse sentido, a filosofia não parte de pressupostos e/ou fundamentos determinados, senão que sua atividade começa desde a diversidade de pressupostos, e isso graças a extensão mesma do conceito de religião. ${ }^{4}$

Numa palavra, nenhuma outra "ciência" se coloca numa posição tão confortável para desenvolver a tarefa analítica e autônoma do fenômeno religioso quanto a filosofia mesma, graças ao cerne que lhe é próprio - como a ciência em geral -, a saber, a universalidade intelectual de seus praticantes. Isso implica dizer que mesmo havendo muitos que discordem da "existência" de um Ser Supremo - o que é bastante saudável -, há um consenso fundamental, i.é., que todos estão convencidos da existência real do fenômeno religioso. Talvez aqui, poderemos encontrar um dos primeiros pressupostos que garante o estatuto da filosofia em meio a pluralidade dos mesmos, no sentido que esse fenômeno religioso se apresenta, em última instância, como um dado real ou como um fato histórico-cultural que permite ser tratado, também, como objeto racional, científico e filosófico. ${ }^{5}$

\section{$2 \mathrm{O}$ espaço da filosofia no âmbito das Religionswissenschaft}

Inicialmente vale remeter ao questionamento evidente desta temática, ou seja, verdadeiramente existe uma "filosofia" apta a inferir "algo" sobre o fenômeno religioso? Parece não ser uma pergunta banal e de fácil resposta, sobretudo quando temos presente a gênese mesma dessa forma peculiar de saber. ${ }^{6}$ Ora, uma das tarefas específicas da filosofia é exatamente a análise dos fenômenos enquanto realidades no e do mundo. Desse modo, os

\footnotetext{
4 Devido a esse pormenor, temos que reconhecer a existência de uma certa bipolaridade de significados em relação à Fundamentaltheologie (Teologia Fundamental), pois esta tem o «principium fidei» como ponto de partida e, também, se coloca a serviço do mesmo. Além disso, de alguma maneira a Teologia Fundamental é, também, uma philosophische Tätigkeit (atividade filosófica), portanto é filosofia, ao desenvolver um tratamento formal da fé, ou seja, sua natureza enquanto tal. Cf. MANCINI, I. Filosofia de la Religión. Concilium, 1980, № 156, p. 404; KüNG, Hans. Existiert Gott? Antwort auf die Gottesfrage der Neuzeit. München: Piper, 1978, p. 187-240. Segundo Hans KüNG, com o advento da moderne Wissenschaft (ciência moderna) emergiu uma nova concepção de Deus, cenário propício ao encontro da Teologia com a Filosofia Moderna, o que levou a romper a antiquada imagem filosófica de Deus.

${ }^{5}$ Cf. Lluís I FONT, Pere. op. cit., p. 14.

6 O Prof. Martínez PORCELl, em Cuestiones Selectas de Metafísica, discorre sobre essa problemática, ainda que limita a questão no marco eminentemente cristão: “[...] ¿Existe un tipo de pensamiento, una clase de filosofía, un modo de acceso a la racionalidad, que nazca directamente de la fe cristiana?" (PORCELL, 2008, p. 17-18). Evidentemente o autor em questão está convencido que sim, ao justificar que há uma relação direta no tocante ao campo objetivo, sendo a filosofia a busca da verdade e, por sua vez, o cristianismo enquanto expressão da verdade (absoluta): "Existe -y no sólo existió en la historia- un pensamiento proprio, una filosofia, que es fruto del encuentro de la razón con la Revelación y la fe Cristiana." (PORCELL, 2008, p. 17).
} 
fenômenos religiosos também são Erscheinungsformen (formas de manifestações) na história, nas culturas, nos povos, independentemente do seu "estilo", rito, crença, origem, etc. Aqui, faz-se mister reconhecer a atuação de uma das disciplinas filosóficas cuja autoridade atua nesse campo, a saber, a Religionsphilosophie (Filosofia da Religião) que, com Hegel - e a partir dele -, ganhou notoriedade. ${ }^{7}$

Essa filosofia da religião assume um duplo sentido, ou seja, busca caracterizar o conjunto interdisciplinar filosófico-científico, cujo objeto de estudo é o próprio fenômeno religioso e, também, busca designar a disciplina filosófica da qual estamos nos referindo e que necessita redefinir-se diante das Religionswissenschaft. Este seria, portanto, a dimensão específica e, neste caso, a de maior interesse face ao nosso tema.

Ao referir-nos ao estatuto filosófico estamos, também, buscando especificar e/ou delimitar o espaço da filosofia naquilo que lhe é próprio (sentido estrito), o que possibilita, ademais, diferenciá-la de outras disciplinas filosóficas - a exemplo do viés filosófico da Natürliche Theologie (Teologia Natural) -, conforme aludimos antes e daquelas disciplinas claramente científicas que formam o conjunto das Religionswissenschaft. Em relação a estas, ou seja, aquelas disciplinas soi-disant (supostamente) filosóficas, a exemplo da teologia natural ou teologia filosófica ${ }^{8}$, cabe-nos uma breve matização na qual fixaremos aquilo que chamaremos de interdisziplinäre Kontrast. A primeira constatação a ser feita sobre a teologia

\footnotetext{
7 A filosofia da religião enquanto disciplina é, desde o ponto de vista histórico, bastante recente e tudo indica que a expressão enquanto tal foi cunhada pelo filho ilustre de Stuttgart, com seu escrito Vorlesungen über die Philosophie der Religion, lições estas proferidas em Berlin. Logo na introdução (edição de 1824), HEGEL assinala e, de alguma maneira assegura a necessidade e importância dessa tarefa filosófica, ao considerar necessário a relação da Filosofia da Religião com a filosofia em geral, conferindo àquela um status - pela sua meta e conteúdo - de "solucionadora ou apaziguadora de todos os enigmas do mundo, de todas as contradições do pensamento profundo" („Ich habe es für nötig erachtet, die Religion für sich zum Gegenstand der philosophischen Betrachtung zu machen und diese Betrachtung als einen besonderen Teil zu dem Ganzen der Philosophie hinzuzufügen”), pois ela se apresenta como "a religião do repouso eterno, da verdade.” („Wir wissen, daß wir uns in der Religion der Zeitlichkeit entrücken und daß sie diejenige Region für unser Bewußtsein ist, in welcher alle Rätsel der Welt gelöst, alle Widersprüche des tiefer sinnenden Gedankens enthüllt sind, alle Schmerzen des Gefühls verstummen, die Region der ewigen Wahrheit, der ewigen Ruhe, des ewigen Friedens"). Cf. Hegel, Georg Wilhelm Friedrich. Vorlesungen über die Philosophie der Religion. Berlin: Duncker und Humblot, 1840, p. 3 (v. I).

${ }^{8}$ Os Essais de Théodicée sur la bonté de Dieu, la liberté de l'homme et l'origine du mal, publicados por Leibniz em 1710 - familiarmente conhecida como Teodiceia -, cujo objetivo fundamental consiste na aproximação da foi com a raison, ainda que mantenha uma certa relação com a filosofia da religião, de algum modo mantém uma nítida distinção, visto que o objetivo da mesma visa, em última instância, explicar a existência do mal e, concomitantemente, justificar a bondade de Deus, investigação esta bastante antiga, pois o mal nunca foi um marco epocal de Leibniz, senão de todos os tempos. Evidentemente, não podemos deixar de reconhecer o mérito deste filósofo, devido o passo gigantesco dado por ele, ou seja, de uma questão problemática à um problema especulativo, uma disciplina filosófica: die Theodizee. A esse respeito ver: FERrATER MorA, José. T. IV, p. 3468-3469; Wegener, R. Das Problem der Theodizee in der Philosophie und Literatur des 18. Jahrhunderts: Mit besonderer Rücksicht auf Kant und Schiller. Berlin: [s.n.], 1909; JANSSEN, H-G. GottFreiheit-Leid: Das Theodizeeproblem in der Philosophie der Neuzeit. Darmstadt: Wissenschaftliche Buchgesellschaft, 1989 (Bd. 74).
} 
natural é, curiosamente, sobre sua recente história também em relação ao seu status mesmo enquanto disciplina filosófica. Isso não implica dizer que os problemas pertinentes a tal esfera são recentes, pois encontramos um interesse gigantesco pelos mesmos, embora tratados

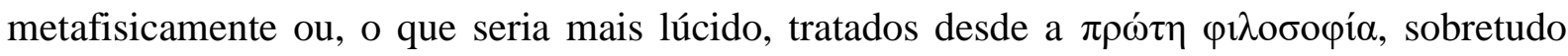
entre os gregos e a longa tradição escolástica. ${ }^{9}$

Assim, quando deparamos com a reflexão filosófica sobre Deus - além de perder a consciência do «intellectus fidei»-, quando se ergue essa disciplina filosófica diferenciada, aí emerge a relação híbrida da teologia com a filosofia, sobretudo com a filosofia da religião e isso, evidentemente, graças aos bons ofícios da metafísica. (Lluís I FONT, 1991, p. 16). Nesse sentido, toda teologia também é uma metalinguagem, pois a mesma necessita permanentemente de dois níveis fundamentais de linguagem: a linguagem religiosa como tal e, fundamentalmente, a metalinguagem filosófica. Talvez por isso, também a teologia natura ou racional enquanto disciplina autônoma, busque tratar os problemas enfrentados com verdadeira autenticidade, ou seja, busca situar seu processo reflexivo tanto no campo da metafísica (sobre o problema do Absoluto, por exemplo), quanto no fenômeno religioso enquanto tal, ou seja, quando este "absoluto" é apreendido pelo nome religioso de "Deus" ou similares.

A pergunta que emerge dessa reflexão pode ser formulada da seguinte maneira: afinal, em que se diferencia Teologia Natural (enquanto disciplina filosófica diferenciada) da Filosofia da Religião? A resposta já foi capciosamente apresentada anteriormente, ao referirse ao aspecto nominativo do ,absolute Sein”. Numa palavra, a diferenciação é que a Religionswissenschaft renuncia a fazer teologia, esta entendida como o lugar natural do tratamento filosófico sobre o tema religioso.

Até aqui tentamos estabelecer a diferenciação da filosofia da religião em relação a uma das disciplinas filosóficas, i.é., a teologia natural ou simplesmente teologia racional ou filosófica. Agora, passaremos a descrever alguns dos aspectos que marcam tal diferenciação entre filosofia da religião (sentido estrito) e as demais disciplinas científicas, ou seja, as Religioswissenschaft que, por sua vez, coincidem com àquela ao estudarem positivamente o

\footnotetext{
9 Uma obra que retrata muito bem esse período foi escrita por Ramon SIBIUDA (1385-1436): Scientia libri creaturarum sive libri naturae et scientia de homine (1434/36), obra esta que influenciaria diretamente a filósofos no talante de Michel Eyquem de Montaigne (1533-1592) e Blaise PASCAL (1623-1662). Vale ressaltar que na segunda edição desta obra (1485), já não encontramos o Liber creaturarum, senão Theologia naturalis demostrando, desse modo, uma forte tendência em busca de uma identidade acadêmica enquanto tal e não mais elucubrações metafísicas, frequentemente dispersas. A esse respeito ver: Montaigne, Michel de. Apologia de Ramon Sibiuda. Barcelona: Edicions 62, 1998, com edição e prólogo de Pere LLUís I FONT.
} 
mesmo objeto, o religiöses Phänomen (fenômeno religioso), portanto um "fato" também sociológico muito além da esfera institucional.

A primeira observação diz respeito a unidade ou pluralidade conceitual, ou seja, se, de fato, se trata das ciências da religião ou da ciência das religiões. Devido a essa complexidade, adotamos a terminologia ciências religiosas que, em última instância, tampouco soluciona tal impasse mas, pelo menos, ameniza a problemática conceitual. Para tal, faremos uma menção, ainda que suscintamente, a três níveis marcadamente cultivados nas Religionswissenschaft, a saber: a história, a sociologia e a psicologia. ${ }^{10}$

A Religionsgeschichte centra sua atenção no conhecimento do passado religioso da humanidade e, com isso, oferece os elementos indispensáveis ao estudo da religião enquanto fenômeno, portanto enquanto religiöses Ereignis (fato religioso). No entanto, basta observar essa "história" para percebermos que a estrutura do seu conhecimento histórico se apresentava quantitativamente reduzida, pois seu foco de pesquisa sempre esteve ligado aos dois eixos mais reconhecidos: as religiões ligadas ao tronco bíblico e aquelas do mundo grego-romano. ${ }^{11}$

Tal limitação indica algo mais profundo, i.é., uma forte e orquestrada tendência em forjar o conceito de "religião" no Ocidente, no intuito de designar o advento do cristianismo e, por extensão, a toda e qualquer manifestação semelhante. ${ }^{12}$

Assim, o cristianismo não seria, portanto, um caso particular de religião, senão que o conceito de religião seria uma generalização a partir do cristianismo. Está claro que o conceito de religião possui uma extensão considerável e, por isso, qualquer resposta simples pode resultar numa grande imprudência. Essa complexidade conceitual apresenta-se como um dado importante às ciências religiosas, pelo menos em dois aspectos: (i) que a determinação mesma do conceito de religião é, sem dúvida, um dos primeiros problemas com que se depara a filosofia da religião e, consequentemente, que este conceito sofrerá alterações segundo a elaboração analítica de cada "tipo" de religião (ii).

No caso da Religionssoziologie, encontramos um certo conditionnement, visto que esta se predispõe a estudar a religião simplesmente como „sozial Phänomen” (fenômeno social). Ora, os critérios que justificam tais condicionamentos poderão ser diversos, a exemplo da interdependência entre fenômeno religioso e sistema cultural, social, político, econômico, etc.

\footnotetext{
10 A escolha dessas três ciências no tratamento do fenômeno religioso enquanto tal não obedeceu a um critério de justificação radical. Talvez o maior rigor esteja centrado na praticidade mesma do conteúdo. Agora, nessa mesma linha, seria oportuno mencionar, por exemplo, a antropologia cultural e/ou as ciências da linguagem, certamente como ciências auxiliares na compreensão do objeto de estudo.

${ }^{11}$ Cf. Lluís I FONT, Pere. op. cit., p. 17.

12 Cf. BARDAJÍ, Alfredo Fierro. Sobre la Religión: descripción y teoría. Madrid: Taurus, 1979, p. 91-95.
} 
Também poderíamos mencionar os componentes sociais da atitude religiosa mesma, além das funções sociais apresentadas pela religião e, não menos importante, as múltiplas formas coletivas de vida religiosa. ${ }^{13}$

Por último, um nível expressivo das Religionswissenschaft consiste em estudar a "religião" como fenômeno psicológico, abrindo espaço a uma série de elementos que os níveis anteriores não haviam contemplados, a exemplo dos condicionamentos psicológicos do comportamento religioso, a interdependência entre comportamento religioso e constituição psicológica, os componentes psicológicos da atitude religiosa, as funções psicológicas da religião e, também, as diferentes formas individuais de comportamento religioso. Trata-se, portanto, da Religionspsychologie.

Essas três ciências - história das religiões, sociologia da religião e psicologia da religião -, não são ciências impermeáveis, ainda que a análise elaborada por cada uma delas seja profundamente particularizada, visto ser este seu caráter imprescindível: o selo de ciência particular. Destarte, tal particularidade permite uma ação coordenada entre elas, o que pode resultar, naturalmente, num tríplice enfoque de uma única ciência, i.é., as ciências religiosas. ${ }^{14}$

As Religionswissenschaft seguem o parâmetro comum da própria conduta científica, ou seja, evita elaborar hipóteses metafísicas e, com isso, explicitam a identidade que lhes compete: "religiosamente neutras e metodologicamente a-ateias". 15

A questão suscitada no tema deste capítulo encontra uma maior ressonância, porque somente agora evidenciamos a problemática relação entre ciência e filosofia. ${ }^{16}$ É verdade que ambas, ciência e filosofia, coincidem no aspecto da vontade, pela qual se constrói um tratamento racional e autônomo do fenômeno religioso. Agora, independentemente dessa

\footnotetext{
13 Possivelmente aqui poderíamos identificar ou, pelo menos, apontar, a grosso modo, a "geografia da religião", sobretudo na análise que se pode fazer sobre os diversos tipos de grupos sociais e econômicos a partir das aglomerações destes demonstrando, fundamentalmente, que na religião se opera, também, diferentes modos de nítida exclusão. No entanto, isso exigiria uma pesquisa mais laboriosa, além de maior condição temporal, realidade inviável neste momento.

14 Essa imbricação presente nos três níveis de ciências particulares, não poucas vezes é analisada como a possibilidade real de uma Religionsanthropologie (antropologia da religião), pois esta permite, exatamente pelo grau de extensão, sintetizar e integrar toda e qualquer "ciência" devido sua raiz fundamental: a complexidade do ser humano. Daí que a pergunta de ordem sapiencial deve ser formulada exatamente em vista da perplexidade deste ser: afinal, quem é o homem?

15 Essa é uma expressão de LLUís I FONT que, embora pareça forte no estilo proposicional, simplesmente expressa que as Religionswissenschaft prescindem da questão sobre a existência de Deus. (LLuís I FONT. op. cit., p. 18).

16 Há uma certa discussão se, de fato, a filosofia ocupa um "lugar" importante no mundo acadêmico. Essa desconfiança tem sua razão de ser quando comparada (a filosofia) com o utilitarismo científico. No entanto, vale ressaltar que a universidade é o lugar por excelência da filosofia, porque nela (na universidade) se reler, produz, projeta e interpreta "culturas". Para esse tipo de tarefa, exige-se, fundamentalmente, domínio da filosofia em vista de atingir certos graus de racionalidade para conceber - concordando ou não -, os critérios éticos, as escolhas políticas e, também, as crenças religiosas.
} 
coincidência, o que a filosofia acrescenta em relação aos três níveis de ciências regionais mencionadas acima? Ainda mais, será que a filosofia enquanto tal, pode oferecer algo a tais ciências?

Inicialmente, e desde a perspectiva da investigação científica (meramente positivista), a filosofia não tem autoridade para "descrever" nada sobre as questões do fato em si. Destarte, as "coisas" não são somente "coisas reais" mas, também, apresentam sentidos, valores, direitos e, além das questões referentes à gênese e a função de cada realidade há, também, a questão da verdade ou da falsidade, inclusive nas afirmações religiosas. ${ }^{17}$

Dito isto, poderíamos afirmar - ainda que provisoriamente -, que a filosofia da religião é uma disciplina filosófica "regional" - mesmo com implicações globais e/ou universais -, exatamente por ser parte da filosofia da cultura, que tem como objetivo esclarecer a natureza, o sentido, as implicações e o valor da religião, e suas relações com o todo do conjunto da cultura, através de uma reflexão sobre o factum das religiões (que estamos tratando como Religionswissenschaft) e uma avaliação crítica das teorias formuladas até nossa época. ${ }^{18}$

\section{0 critério de legitimação entre a Filosofia e as Religionswissenschaft}

A tradição do pensamento ocidental, desde seu advento, teve como objetivo primeiro interpretar o mundo e a vida enquanto tal constituindo-se, assim, numa "fase pré-filosófica",

\footnotetext{
17 Pelo menos dois autores nos ensinam a distinguir entre as questões de gênese e as questões de valor. $\mathrm{O}$ primeiro deles é o conterrâneo de Sigmund FREUd (1856-1939), o checo Edmund HuSSERL (1859-1938), numa das lições publicadas num tempo peculiar da história recente (1928) e organizadas, também, por um autor contemporâneo explicitamente controverso, Martin HEIDEGGER (1889-1976): Vorlesungen zur Phänomenologie des inneren Zeitbewußtseins (Lições de fenomenologia da consciência interna do tempo), sobretudo o terceiro capítulo da primeira parte: Die Konstitutionstufen der Zeit und der Zeitobjekte (os níveis de constituição do tempo e os objetos temporais). Cf. HuSSERL, Edmund. Vorlesungen zur Phänomenologie des inneren Zeitbewußtseins. Freiburg: Max Niemeyer, 1928. O segundo autor é o alemão Max SCHELER (1874-1928), com duas de suas obras mais emblemáticas: Der Formalismus in der Ethik und die materiale Wertethik (1913/16) und Vom Wesen der Philosophie und der moralischen Bedingung des philosophischen Erkennens (1917) [O formalismo na ética e a ética material dos valores e A essência da filosofia e a condição moral do conhecer filosófico], esta organizada no conjunto dos estudos Vom Ewigen im Menschen (Do eterno no homem).

18 Explicitamos aqui uma certa concepção descontinuísta no referente as relações entre Wissenschaft e Philosophie, cujo resultado imediato consiste em que esta, a filosofia, não universaliza seus "resultados" como o faz a ciência, pois Filosofia e Ciência tratam de responder, em última instância, a perguntas diferentes. O conflito nessa relação, sobretudo em si tratando da filosofia da religião, começa na dependência das Religionswissenschaft sobre o "banco de informações" próprio desse tipo de ciência (ciências religiosas), no intuito de ter acesso ao conteúdo mesmo. Isto já implica que seu conhecimento, além de dependente, também é deveras limitado. Ignorar essa dependência, ou melhor, esse "éclat de la Science » seria, portanto, tentar moverse num profundo vazio. Ademais, sua atividade não poderia começar até que as ciências pudessem acabar com essa exaustiva tarefa, pois do contrário, ela (a filosofia) não poderia começar jamais.
} 
ainda que tal expressão esteja mal formulada, mesmo reconhecendo a grandeza mencionada pelo Estagirita. ${ }^{19}$

Encontramos na antiguidade as posições elementares da filosofia na relação com a religião e tal posição assumiu sempre uma Tendenz (atingindo seu ápice com a Aufklärung) de superação da religião, mas sem deixar de absolvê-la. ${ }^{20}$

Naturalmente, esta situação pressupõe, ao menos implicitamente, uma concepção da religião e da filosofia: a religião aparece, não somente como instância soteriológica mas, também, como concepção do mundo e, por sua vez, a filosofia surge não só como a obra da razão, senão como uma dogmática herdada. ${ }^{21}$

Não obstante as diferenças e peculiaridades existentes entre a filosofia e a religião encontramos, no marco histórico atual, um novo tratamento do fenômeno religioso que, agora, pode ser qualificado de filosófico ou científico, segundo o caso específico, e isso graças a um desejo explícito de instaurar «la paix religieuse ».

Essa "nova etapa" da filosofia sedimenta o critério de legitimação na relação estabelecida com as ciências religiosas, pois o núcleo que lhe garante esse selo está no papel crítico assumido por ela (pela filosofia), agora com os olhos da modernidade. ${ }^{22}$

19 Aristóteles reconhece esse esforço racional presente naqueles que iniciaram tal atividade antes do "surgimento" dos filósofos: «Segundo alguns, também os primeiros autores de cosmogonias, antiquíssimos e

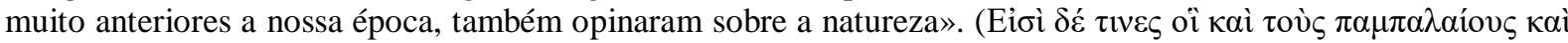

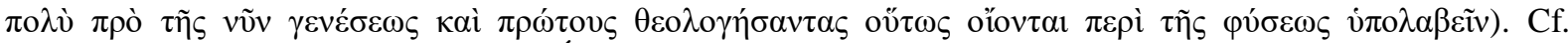
ARISTOTELES, Metaph., A 3, 983 ${ }^{\mathrm{b}}$. Em Émile BRÉHIER, encontramos uma formulação extremamente séria sobre essa problemática, na medida em que questiona as verdadeiras origens da filosofia, ou seja, se essa patente pode ser atribuída ao mundo grego ou se encontramos resquícios dessa forma de pensar em outras manifestações culturais, ainda que, ao dedicar-se a descrever os pré-socráticos, o mesmo, i.é., BRÉHIER, cai na tentação histórica, ou seja, no tratamento convencional sobre os primeiros filósofos: «Quins són els orígens i quines són les fronteres de la filosofia? Va començar la filosofia al segle VI, a las ciutats jòniques, com admet una tradició que es remunta a Aristòtil? O té un origen més antic, sia als mateixos països grecs, sia als països orientals? L'historiador de la filosofia pot i deu restringir-se a seguir el desenvolupament de la filosofia a Grècia i als països de civilització d'origen grecoromà, o bé ha d'ampliar la seva visió fins a les civilitzacions orientals?» [Cf. BRÉHIER, Émile. Historia de la Filosofia: Antiguitat $i$ edat mitjana, 1998, p. 19-20. (v. 1)].

20 É sabido que esse embate ocorre com o cristianismo, sobretudo na relação entre razão e fé, marcadamente assumido por Santo Agostinho ao interpretar a fé metafisicamente, ou seja, uma tentativa muito bem elaborada (e aqui muito se deve aos Padres da Igreja) de separar duas vias possíveis de filosofia: uma cristã - a "verdadeira filosofia" segundo seus seguidores -, e outra pagã. No entanto, tal "concorrência" chega a ser desleal em si mesma, visto que "ambas" buscam o mesmo objetivo, ou seja, a busca pela sabedoria.

21 A Patrística consiste, nesse sentido, numa obra fundamentalmente teológica e somente implicitamente ou acidentalmente explícita, se pode encontrar elementos de uma filosofia, neste caso, de uma filosofia da religião. O mesmo critério pode ser aplicado aos medievais, i.é., a filosofia como ancilla theologiae e sua impossibilidade teórica de distanciamento metodológico, acabou impossibilitando pensar a filosofia enquanto tal. Vejamos a observação de Henry DUMÉRY, mesmo reconhecendo seu exagero mas, também, sua razão de ser: "São Tomás, ao admitir as duas ordens de verdades, decidiu a sorte da filosofia moderna." (Cf. DUMERY, H. Phénoménologie et Religion: Structures de l'institution chrétienne. Paris: PUF, 1962, p. 92).

22 Grande parte desse esforço em vista da legitimação partiu, pelo menos, de dois grupos bem definidos: por um lado os declarados "livres" das amarras da fé e, por outro, das mulheres e homens egressus da ortodoxia eclesial. 
Não se trata, portanto, da preocupação dominante até o século $\mathrm{XX}$, a preocupação religiosa ou antirreligiosa mas, fundamentalmente, na ousada perspectiva consciencial em compreender o fenômeno religioso enquanto tal. Assim, a atitude filosófica frente a ele (ao fenômeno religioso) não passa pelo crivo da defesa, da superação ou da condenação mas, simplesmente, em buscar entendê-lo com as ferramentas inerentes do processo crítico. Nesta tarefa, a filosofia se utiliza de dois métodos importantes já mencionados anteriormente: a fenomenologia e a análise da linguagem, pois ambos coincidem na mesma perspectiva e/ou interesse: entender a especificidade e/ou identidade do fenômeno religioso, não obstante as diferentes linhas de pesquisa dos fenomenólogos, ou seja, a linha mais historicista ou da própria filosofia. ${ }^{23}$

Dito isto, podemos afirmar que o critério legitimador da filosofia na relação estabelecida com as ciências religiosas passa, exatamente pela sua própria opção filosófica, ou seja, assumir sua originalidade crítica e jamais doutrinária, com preocupações apologéticas ou antirreligiosas completamente desnecessário. Daí que frente as demais ciências, a filosofia estará ocupando sempre uma posição de desconforto, pois a desconfiança faz parte de sua própria "estrutura genética", diferentemente daquelas "ciências" que dizem ter encontrado um "lugar" de paz e tranquilidade. Numa palavra, a filosofia sempre foi - e seguirá sendo -, o 'lugar' do « inconfort intellectuel », porque ela se apresenta, em última instância, como uma (cons)ciência problematizadora. ${ }^{24}$

\footnotetext{
23 Nessas duas perspectivas, faz-se mister destacar alguns nomes importantes, a exemplo de Gerardus van der LeEuw (1890-1950), Mircea EliAde (1907-1986) e Geo WIDENGREN (1907-1996), estes na perspectiva historicista e Max SCHELER (1874-1928), Rudolf OTTO (1869-1937) e Henry DUMÉRY (1920-2012) na perspectiva mesma da descrição do fenômeno. Evidentemente, o nome que mais se sobressai na perspectiva da análise da linguagem como segundo método usado pela filosofia na compreensão do fenômeno religioso é, sem dúvida, Ludwig WiTTGENSTEIN (1889-1951), este situado em dois níveis de um mesmo centro de interesse: o problema da verificação dos enunciados religiosos e a descrição mesma das características da linguagem religiosa, tendência esta que o aproxima, também, da postura fenomenológica.

24 Possivelmente essa legitimação da filosofia através da postura crítica como critério fundamental e de identidade gera aquilo que LLUís I FONT chama de "dificuldades internas", ou seja, um tipo de aporia que, aparentemente, limitaria sua tarefa crítica, ou ainda, sua legitimidade enquanto tal. A eminência dessa aporia é possível somente quanto há um esforço para desautorizar a importância das concepções mencionadas notadamente dogmáticas - que, sem a distinção dos dois níveis de linguagem (religioso e filosófico) resultaria insustentáveis. Numa palavra, a filosofia (da religião) parece ser um dimensão impraticável, tanto para o ser humano a-religioso, pois este carece da religiöse Erfahrung e, por isso, não pode falar daquilo que não conhece, quanto ao religioso, porque sua fé ficaria ameaçada, exatamente pelo exercício da autonomia intelectual. Sem dúvida é importante conhecer o próprio objeto de reflexão - neste caso, o objeto religioso -, mas não parece imprescindível ter uma experiência religiosa especial. Afinal, poderíamos dizer que é possível filosofar sobre a religião (religiões) sem a necessidade de ser religioso, da mesma forma filosofar sobre a ciência (ciências) sem ser cientista, ou ainda, filosofar sobre a moral, sem ser virtuoso, uma realidade muito presente em nosso contexto.
} 


\section{Aspectos conclusivos}

Falando sobre a riqueza poliédrica dos indivíduos, comenta o jovem filósofo MENDLEWICZ: "Neste sentido, o antropologismo que emana desta postura se legitima, sobretudo nas ciências humanas, pela própria vivência espiritual da época. E a primeira reflexão que interessa ao homem é, precisamente, ele mesmo [...]”. (SEGURÓ MENDLEWICZ, 2013, p. 212). Ora, para que a filosofia encontre seu espaço no âmbito das ciências religiosas sedimentando, desse modo, sua própria identidade (estatuto), necessita voltar seu olhar não somente a este "ele mesmo" (este ser humano), senão a tudo aquilo que está ao seu redor e, por isso, constitui espaços possíveis de conhecimento e, sobretudo, espaços de experiência vital. O fenômeno religioso é, sem dúvida, um desses inúmeros espaços possibilitadores dessa experiência vital.

Para elaborar esse processo, nada melhor que recorrer aquela ciência que introduz esse indivíduo na atividade mesma da razão ou no processo racional que, às vezes, tem-se mostrado enormemente perigoso ao enveredar-se na busca enlouquecida do domínio e, portanto, do poder.

Esse fenômeno religioso do qual falamos tantas vezes, ultrapassa seus próprios limites e, em sua condição de experiência real tem, evidentemente, desenvolvido um papel singular em diversas esferas que, aparentemente, não usam a roupagem confessional. O que estamos dizendo é que o ferrenho impacto da crítica moderna em relação ao desaparecimento do fato religioso, este tido como um "comportamento" do passado longínquo e, portanto, superado pelo advento e progresso das ciências e do novo rosto democrático, parece não ter sentido os efeitos esperados. A grandiosidade desse fenômeno religioso (das religiões) consiste, portanto, na constante atualização de seus elementos - todos eles vinculados a uma certa dimensão transcendente -, às novas gerações, sobretudo, aquelas formadas dentro da perspectiva profundamente racionalista. Junto a essa "estratégia" - que incialmente não se apresenta desonesta -, cabe à filosofia desenvolver sua tarefa, cujo foco de atenção será sempre entender esse fenômeno, evidenciar suas mudanças, detectar sua vigência, deixando para outras ciências a difícil tarefa de aceitar ou rejeitar, valorizar ou degradar... estimar ou menosprezar. Talvez, nesse processo de evidenciação do estatuto da filosofia no âmbito das Religionswissenschaft, deparamo-nos com sua dupla e (in)esperada condição: sua grandeza e sua miséria. 


\section{Referências}

ARISTÓTELES. Metafísica. Tradução de Valentín García Yebra. ed. 2., reimp. 3. Madrid: Gredos, 1998. (Edición trilingüe).

BRÉHIER, Émile. Història de la Filosofia: Antiguitat $i$ edat mitjana. Tradução de Antoni Vicens. Barcelona: Tecnos, 1998. (v. 1).

DUMERY, H. Phénoménologie et Religion: Structures de l'institution chrétienne. Paris: PUF, 1962.

FERRATER MORA, José. Diccionario de Filosofía. 2. ed. rev. e ampl. Barcelona: Ariel, 2009.

FIERRO BARDAJÍ, Alfredo. Sobre la Religión: descripción y teoría. Madrid: Taurus, 1979.

HEGEL, Georg Wilhelm Friedrich. Vorlesungen über die Philosophie der Religion. Berlin: Duncker und Humblot, 1840.

Husserl, Edmund. Vorlesungen zur Phänomenologie des inneren Zeitbewußtseins. Freiburg: Max Niemeyer, 1928.

JANSSEN, Hans-Gerd. Gott - Freiheit - Leid: das Theodizeeproblem in der Philosophie der Neuzeit. Darmstadt: Wissenschaftliche Buchgesellschaft, 1989.

KÜNG, Hans. Existiert Gott? Antwort auf die Gottesfrage der Neuzeit. München: Piper, 1978.

Lluís I FOnT, Pere. L'estatut de la Filosofia de la Religió. 1991. 26f. Apostilha (Livre docência) - Universitat Autònoma, Barcelona.

MANCINI, Italo. Filosofia de la Religión. In: Concilium, Petrópolis: Vozes, n. 156, 1980.

Montaigne, Michel de. Apologia de Ramon Sibiuda. Barcelona: Edicions 62, 1998.

Porcell, Martínez. Dios, Persona y Conocimiento: cuestiones selectas de metafísica. Barcelona: Balmes, 2008. (Biblioteca Filosófica de Balmesiana, Serie I, v. V).

SCHELER, Max. Der Formalismus in der Ethik und die materiale Wertethik: Neuer Versuch der Grundlegung eines ethischen Personalismus. Freiburg: Max Niemeyer, 1916.

SchELER, Max. Vom Ewigen im Menschen. Leipzig: Der Neue Geist, 1919.

Seguró Mendlewicz, Miquel. Exigències d'una filosofia de la religió, avui. In: Ars Brevis. Barcelona: Universitat Ramon Llull, n. 19, 2013.

SouZA, J. C. A. O Projeto da Modernidade: autonomia, secularização e novas perspectivas. Brasília: Liber Livro, 2005.

Wegener, R. Das Problem der Theodizee in der Philosophie und Literatur des 18. Jahrhunderts: Mit besonderer Rücksicht auf Kant und Schiller. Berlin: [s.n.], 1909. 